\title{
Adecuación de la acción de lesividad a los medios de control contemplados en la Ley 1437 del $2011^{*}$
}

\author{
Adaptation of the Harmful Action to the Means \\ of Control Contemplated in Law 1437 of 2011
}

\author{
Rodolfo Torregrosa Jiménez* \\ Nayibe Alexandra Villalba García**
}

Fecha de recepción: 5 de mayo del 2020

Fecha de aprobación: 25 de mayo del 2020

\section{RESUMEN}

Al amparo de la exigencia de armonizar los actos administrativos con el ordenamiento jurídico que les es superior, se consagró en la Ley 1437 del 2011, en el apartado que trata sobre la revocatoria directa de actos administrativos con incidencia en situaciones particular y concretas, la obligación, para la entidad que emitió la decisión, de demandarla ante la Jurisdicción de lo Contencioso Administrativo, con el fin de expelerla del orden legal, ante la ausencia de consentimiento del particular para revocarla. No obstante, este asomo de actuación judicial no es desarrollado en la mencionada Ley, por lo que su uso y comprensión refleja una diversidad de planteamientos tanto jurídicos como doctrinarios, especialmente en torno al mecanismo que debe ser utilizado por el ente accionante para acceder a

Artículo de revisión enmarcado dentro del proyecto de investigación "Análisis de la política pública: ley de restitución de tierras", del grupo de investigación Derecho, Sociedad y Estudios Internacionales, línea de Justicia Transicional, de la Universidad Libre, seccional de Bogotá.

Citar como: Torregrosa Jiménez, R. y Villalba García, N. A. (2020). Adecuación de la acción de lesividad a los medios de control contemplados en la Ley 1437 del 2011. Via Inveniendi et Iudicandi, 15(2), 297-319. DOI: https://doi.org/10.15332/19090528/6252

** Doctor en Sociología Jurídica por la Universidad Externado de Colombia y magíster en Ciencia Política por la Universidad de los Andes; docente investigador de la Universidad Libre, sede de La Candelaria. Pertenece al grupo de investigación Derecho, Sociedad y Estudios Internacionales, cVlac: https://bit.ly/2N6Dm7E. Correo: rodolfoa.torregrosaj@unilibre.edu.co. ORCID: 0000-0001-6369-8547

*** Especialista y candidata a magíster en Derecho Público por la Universidad Autónoma de Colombia; abogada. Correo: nayibea.villalbag@gmail.com. ORCID: 0000-0002-7185-1617 
la administración de justicia, frente a su pretensión de lesividad, por cuanto los medios de control enlistados en este código no se refieren específicamente a esta modalidad de pretensión.

Así las cosas, en este artículo se presenta parte de la discusión que se ha forjado en el escenario jurídico colombiano a partir de la promulgación de la Ley 1437 del 2011, respecto de la llamada acción de lesividad, con lo que se atiende un elemento sustancial en la adecuación de un medio de control a una pretensión específica, cual es la caducidad. Del mismo modo, se evidencia la evolución de la herramienta procesal en lesividad, para ultimar la comprensión que en la actualidad se tiene sobre ella.

Palabras clave: acción de lesividad, medio de control, nulidad y restablecimiento del derecho, acto administrativo, revocatoria.

\section{Abstract}

Law 1437 of 2011 was enshrined to protect the legislative system by harmonizing administrative acts with superior legal systems. In the section that addresses the direct reversal of administrative procedures with incidence in particular and concrete situations, the entity who emits the decision has the obligation to sue it before the Administrative Law Jurisdiction, in order to expel it from the legal order, when the decision is detrimental to the public interest. However, this aspect of judicial proceedings is not developed in the aforementioned Law, so its use and concept reflect a diversity of legal and doctrinal approaches, especially with regard to the mechanism used by the petitioner entity to gain access to the administration of justice, vis-à-vis detrimental action, considering the fact that the supervisory measures enlisted in this Code do not make a specific referent to this form of claim. Thus, this article presents part of the discussion that has been forged in the Colombian legal scenario since the promulgation of Law 1437 of 2011, regarding the so-called detrimental action, which addresses a substantial element in the adequacy of a means of control for a specific claim, namely, expiration. Likewise, the evolution of the detrimental action will be traced, so as to understand the current understanding about it.

Keywords: action of injury, means of control, nullity and restoration of the right, administrative act, revocation. 
Rodolfo Torregrosa Jiménez, Nayibe Alexandra Villalba García

\section{INTRODUCCIÓN}

Este escrito aborda la discusión que se presenta en la aplicación de los medios de control, cuando se utilizan en la modalidad de lesividad como mecanismo de revisión de actos administrativos de contenido particular en los que la entidad pretende anular su propia decisión.

Bajo este supuesto, resulta oportuno precisar que la Ley 1437 de 2011, en el capítulo de medios de control, dispone doce mecanismos diferentes para verificar en sede judicial las actuaciones de la administración. Una de estas, consagrada en el artículo 138 de la mencionada ley, es la denominada nulidad y restablecimiento del derecho, consistente en la posibilidad que tienen las personas de demandar la nulidad de actos administrativos de contenido particular y concreto para obtener consecuentemente el restablecimiento del derecho que les hubiere sido conculcado por la respectiva autoridad, con el acto administrativo demandado.

No obstante la precisión anterior, ocurre también que en el artículo 97 de esta misma codificación se brinda la oportunidad a la respectiva autoridad de demandar su propia decisión ante la jurisdicción contencioso administrativa, cuando considere que su acto se encuentra vigente contrariando la Constitución o la ley; sin embargo, esta disposición abre la puerta a una modalidad sui géneris de medio de control, pues, pese a no encontrarse explícitamente enunciado dentro del listado de medios de control, en este se referencia una alternativa procesal que, por vía de interpretación, podría inicialmente adecuarse a las previsiones del referido artículo 138. De modo, pues, que este proceso se adelantaría por vía del medio de control de nulidad y restablecimiento del derecho en la modalidad lesividad, como lo ha denominado la jurisprudencia y la doctrina, pues a través de este se declararía la anulación de un acto administrativo y, en consecuencia, se daría el restablecimiento del derecho en favor de la entidad accionante.

Así las cosas, se observa un posible vacío normativo que da paso a diversos postulados conceptuales en torno a la acción de lesividad, pues al no existir como una modalidad autónoma de pretensión, su definición y uso, muchas veces inadecuado, responde a la diversidad de interpretaciones suscitadas al respecto. En esta medida, el presente escrito aborda una revisión bibliográfica frente a distintos autores que se han pronunciado 
respecto del ejercicio de esta modalidad de acción. Se deja ver de esta forma la manera en que es entendida en la actualidad dicha actuación procesal.

En este orden, el objetivo del presente artículo de revisión consiste en identificar las vertientes de aplicación procesal que, en torno a la acción de lesividad, se han acogido en el marco de los medios de control fijados en el Código de Procedimiento Administrativo y de lo Contencioso Administrativo, en Colombia.

\section{Debate}

Con la promulgación de la Ley 1437 del 2011, por la cual se expidió el Código de Procedimiento Administrativo y de lo Contencioso Administrativo (CPACA), se efectuó, entre otras, una actualización de los instrumentos procesales en Colombia, respecto de un área específica del derecho, relacionada con el control judicial de actuaciones surtidas en ejercicio de la función pública. Una de las variaciones sustanciales que trajo esta disposición en el trámite procedimental fue el tránsito de la escrituralidad a la oralidad, en esta jurisdicción (Millán Durán, Blanco Alvarado y Guecha Medina, 2017).

Además, este código introdujo en el sistema procesal colombiano la sustitución de las denominadas acciones contencioso administrativas, por el concepto de medios de control. $\mathrm{Al}$ respecto, en la exposición de motivos de la mencionada ley se señaló:

El proyecto propone cambiar el actual sistema que parte de la existencia de una pluralidad de acciones, por considerar que el derecho a accionar es uno y único, como una de las manifestaciones del derecho fundamental de acceso a la justicia, de manera que, su unificación en un solo esquema procesal, evita que se haga nugatorio el acceso a la justicia por equivocaciones, por parte de los usuarios, en la selección del medio de control adecuado para acceder a la jurisdicción. (Senado de la República, 2009)

En este contexto, se gestó una nueva mirada a los mecanismos judiciales para verificar las distintas actuaciones de la administración; estas se concretan, según su pretensión específica, en una amplia gama de opciones contenidas en el título III de la parte segunda 
Rodolfo Torregrosa Jiménez, Nayibe Alexandra Villalba García

de la Ley 1437 del 2011, que incorporan, para el efecto y como medio de control, lo siguiente: la nulidad por inconstitucionalidad, el control inmediato de legalidad, la nulidad, la nulidad y restablecimiento del derecho, la nulidad electoral, la reparación directa, las controversias contractuales, la repetición, la pérdida de investidura, la protección de los derechos e intereses colectivos, la reparación de los perjuicios causados a un grupo, el cumplimiento de normas con fuerza material de ley o de actos administrativos y la nulidad de las cartas de naturaleza (Aldana y Guarín, 2016).

Bajo este panorama, resulta pertinente la revisión bibliográfica adelantada en este escrito, pues en la anterior enunciación no se hace alusión alguna a la tradicionalmente denominada acción de lesividad, lo que sugiere que, con la implementación del CPACA, su consagración y uso desapareció. Sin embargo, debe decirse que el artículo 97 del referido código, que trata sobre la revocatoria de actos administrativos creadores de situaciones jurídicas particulares y concretas, regula la forma en la que en sede administrativa podría revocarse este tipo de decisiones, exigiendo, para el efecto, el consentimiento del titular; no obstante, los incisos segundo y tercero de este artículo se refieren a la posibilidad que tiene la autoridad emisora del acto administrativo de que, ante la ausencia de consentimiento del titular, lo demande ante la jurisdicción contencioso administrativa.

Es así como se advierte una discontinuidad en el cuerpo normativo del código, pues refiere una demanda contenciosa en un apartado que no corresponde al de los medios de control; sin embargo, esta ambigüedad es tratada por la doctrina, como pasa a evidenciarse, mediante la aplicación extensiva de los medios de control enlistados en los artículos 137 y 138 del CPACA, bajo la denominación de lesividad, lo que evidentemente configura un escenario de confusión e inestabilidad jurídica con respecto a esta herramienta procesal.

En este orden, resulta pertinente partir del siguiente planteamiento:

Entonces, en este contexto, la pregunta es ¿qué acción debe interponer la administración, la simple nulidad o la nulidad y restablecimiento de derecho? La respuesta depende de lo que la entidad finalmente persiga, lo que debemos tener claro es que el Estado puede ejercer en lesividad, cualquiera de las dos acciones. Si lo que pretende la entidad, es la salvaguarda del estado de derecho, 
que el acto administrativo esté de acuerdo con la Constitución y las leyes, la acción que debe incoar es la de nulidad, pero si lo que persigue la entidad, es la nulidad del acto, pero que al mismo tiempo se restablezca su derecho, el resarcimiento del perjurio padecido tendrá que acudir ineluctablemente a la nulidad y restablecimiento de derecho. (Díaz Roa, Hernández González y Galvis Flóres, n.d., p. 20)

Ante esta interpelación, Fajardo (2015) también reconoce la omisión normativa en torno de esta forma de pretensión contenciosa, pese a asegurar que en Colombia la acción de lesividad tiene fundamento constitucional en los artículos 2, 4, 121, 122, 123 inc. 2, 209 y 230, entre otros, como expresión de los principios de prevalencia del ordenamiento constitucional y de legalidad, a la vez que determina, en el marco legal, para el autor, la denominada acción de lesividad:

A partir de la vigencia de la L.1437/2011, se encuentra inmersa en el medio de control de nulidad con restablecimiento del derecho, pues no está regulada en ninguna disposición normativa como una acción autónoma e independiente, aunque otrora se deducía del C.C.A., especialmente cuando se estudiaba el tema de caducidad de las acciones, “art. 136-2”. (2015, pág. 61)

En este sentido, Fajardo afirma que actualmente la regulación del medio de control en modalidad lesividad se deriva de los artículos 97, 159, 161 y 164 de la Ley 1437 de 2011, deduciendo de estas normas que el concepto de acción de lesividad en el sistema colombiano implica que

[...] las autoridades administrativas están obligadas a demandar el acto administrativo, que haya creado o modificado una situación jurídica de carácter particular y concreto, o reconocido un derecho de igual categoría cuando no hubiere el consentimiento previo, expreso y escrito del respectivo titular para revocarlo, así considere la autoridad que el acto es contrario a la Constitución o a la ley, o haya sido expedido por medios ilegales o fraudulentos, a través de los medios de control pertinentes, ya sea de nulidad, en el evento de que el acto administrativo demandado sea de carácter particular y esté acorde con el artículo 137 del CPACA, pudiéndose presentar la demanda ante la jurisdicción 
Rodolfo Torregrosa Jiménez, Nayibe Alexandra Villalba García Adecuación de la acción de lesividad a los medios de control contemplados en la Ley 1437 del 2011

en cualquier tiempo o, a través de la nulidad y restablecimiento del derecho (art. 138), cuando se pretenda el restablecimiento automático del derecho, debiéndose acudir dentro de los cuatro (4) meses siguientes contados a partir del día siguiente de la comunicación, notificación, ejecución o publicación del acto administrativo, o cuando se trata sobre prestaciones periódicas, también se pueden demandar en cualquier tiempo. (2015, pp. 61-62)

Es decir, el autor propone la acción de lesividad en el marco del medio de control de nulidad y restablecimiento del derecho, a partir de un recorrido histórico de las acciones que se han promovido en el Estado colombiano para la anulación de un acto administrativo de contenido particular y el consecuente restablecimiento del derecho afectado; no obstante, según el autor, el espectro del medio de control aplicable se amplía, haciendo uso de la teoría de los móviles y finalidades, a fin de evidenciar la posibilidad de enjuiciar, mediante la simple nulidad, un acto administrativo particular del que no se deriva automáticamente el restablecimiento de ningún derecho, únicamente la eliminación del ordenamiento jurídico de un acto contrario a las normas superiores.

Sucintamente, Fajardo (2015) plantea que

[...] la acción de lesividad es el mismo medio de control de nulidad y restablecimiento del derecho, cuando lo ejerce la autoridad administrativa, por tal razón persigue las mismas pretensiones de los particulares cuando lo incoan ante la jurisdicción contencioso administrativa, medio de control a través del cual se puede solicitar: "la nulidad del acto administrativo, el restablecimiento del derecho y la reparación del daño". (p. 50)

En comunión con lo hasta acá señalado, en la obra de González, Martínez y Rodríguez (2018), que tiene como objetivo encontrar mecanismos no jurisdiccionales con los que se puedan modificar actos administrativos particulares en los que se haya cometido un error por parte de la administración, para evitar recurrir a la acción de lesividad, se sugiere que

[...] la acción de lesividad no se encuentra regulada en Colombia y su aplicación se da por analogía con los medios de control de nulidad simple (artículo 137) y nulidad y restablecimiento del derecho (artículo 138) descritos en la 
actualidad en el Código de Procedimiento Administrativo y de lo Contencioso Administrativo, Ley 1437 de 2011. (p. 21)

Hasta este punto se observa que, para estos autores, ante la evidente omisión normativa, el ejercicio judicial en lesividad admite tramitarse mediante los medios de control de nulidad y de nulidad y restablecimiento del derecho, indistintamente del escenario de expedición del acto administrativo de contenido particular y concreto.

Sumándose a esta postura, en el específico marco de los actos emitidos en la contratación estatal, Puentes (2019) asegura que:

Una nota característica y de alto relieve tanto para la Ley 1437 de 2011, como para el Decreto 01 de 1984, anterior Código Contencioso Administrativo, es que no se preocuparon por consagrar la acción de lesividad como una acción autónoma e independiente, pero su ejercicio puede, como bien se afirmó en anteriores párrafos, realizarse a través de las acciones de nulidad y nulidad y restablecimiento del derecho, de acuerdo a si la pretensión lleva inmersa la declaración de restablecimiento del derecho o no.

Según la Ley 1437 de 2011, si en ejercicio de la acción de lesividad la pretensión es de simple nulidad, es decir, las pretensiones se relacionan únicamente con la tutela del orden jurídico y la legalidad en abstracto y no se está solicitando el restablecimiento de ningún derecho, la acción de lesividad puede ejercerse en cualquier tiempo a partir de la expedición, comunicación, notificación, ejecución o publicación del acto. Si por lo contrario lo que se persigue con la solicitud de nulidad del acto es el restablecimiento de un derecho, el término de caducidad de la respectiva acción será de cuatro (4) meses contados a partir del día siguiente de la expedición, comunicación, notificación, ejecución o publicación del acto. (p. 23,24)

Es precisamente esta última afirmación la que suscita la divergencia de posturas que se mostrará a continuación, ya que la caducidad del medio de control es un elemento que habilita o impide el acceso a la administración de justicia por parte de la jurisdicción contencioso administrativa, de conformidad con el numeral $1 .^{\circ}$ del artículo 169 del CPACA, 
Rodolfo Torregrosa Jiménez, Nayibe Alexandra Villalba García

que impone el rechazo de la demanda cuando ha acontecido este fenómeno. Resulta entonces indispensable resaltar el contraste en la postura de aplicación de la lesividad, mostrando que, para otros autores, el uso no puede ser tan amplio como se ha dicho hasta acá — entre la nulidad y la nulidad y restablecimiento del derecho_- pues, como se señala en la cita anterior, en las oportunidades para presentar la demanda, que regula el artículo 164 del CPACA, la pretensión enmarcada en la nulidad consagrada en el artículo 137 puede ser presentada en cualquier tiempo, mientras que la de nulidad y restablecimiento del derecho deberá presentarse dentro del término de cuatro meses.

En exploración de esta premisa, debe destacarse que justamente con la promulgación del CPACA se dio paso a la discusión que se expone en este artículo respecto de la adecuación de la lesividad a los medios de control de que dispone la referida codificación, pues el derogado Código Contencioso Administrativo (Decreto 01/84) contenía una alusión a la acción de lesividad, concretamente sobre el término con el que contaba la entidad demandante para presentar la demanda en el numeral $7 .^{\circ}$ del artículo 136 , con referencia al término de caducidad, que disponía esto: "Cuando una persona de derecho público demande su propio acto la caducidad será de dos (2) años, contados a partir del día siguiente al de su expedición".

Así las cosas, pese a la reducida regulación que en el código anterior se tenía sobre la acción de lesividad, este por lo menos definía un término explícito de caducidad para promoverla, asunto que el legislador omitió en el CPACA, pues la norma vigente no se pronuncia en forma expresa siquiera sobre este elemento procesal. Sin embargo, existen posturas doctrinarias en las que se asegura que este vacío normativo, ocasionado en el cambio de legislación, "no quiere decir que haya desaparecido del orden jurídico administrativo. Lo anterior quiere decir que, la acción de lesividad hoy está sujeta al mismo término consagrado para la acción contencioso administrativo con pretensión de nulidad y restablecimiento del derecho" (Pereira Blanco, 2013, p. 50).

Nótese cómo a partir de esta idea se da elección preponderante a este medio de control, de modo que, en los ejercicios académicos, a efectos de dar claridad sobre instituciones procesales de la pretensión de lesividad, se plantea que la caducidad de este medio de control es de cuatro meses, bajo el entendido de que su trámite responde al procedimiento establecido para la nulidad y restablecimiento del derecho. Esta conclusión, pese 
a ser aceptada por una parte de la doctrina, lleva inmersa la preocupación que sobre este elemento manifiestan Pacheco y Santos (2014), al seńalar que
[...] la reducción del término de caducidad de dos años a cuatro meses hace que se imposibilite el ejercicio de la acción de lesividad, pues la inconstitucionalidad o ilegalidad de los actos muchas veces sobreviene posterior a la notificación del mismo, coartando la finalidad última de la acción. (pp. 21-22)

Aunado a que la misma divergencia de criterios respecto de la aplicación de este medio de control "no da asomos de estabilidad jurídica, bajo el entendido que las posturas frente a la misma varían dependiendo de la corporación, e inclusive muchas veces entre las salas que las conforman” (Moreno Baquero, Romero Espinal y Romero Ladino, 2015, p. 30). Esta afirmación resulta muy acertada en el panorama descrito, más cuando abundan decisiones emitidas por el órgano de cierre de la jurisdicción contencioso administrativa en las que se asumen posturas discordantes en la aplicación de la acción de lesividad.

A modo ilustrativo, resulta oportuno citar una decisión del Consejo de Estado, Sección Tercera (9 de julio del 2014), en la que se pronunció sobre el tema con ocasión de una demanda en la que se controvertía el acto administrativo a través del cual un municipio había adjudicado un contrato dentro de un proceso de selección abreviada de menor cuantía, pues se advirtió por parte del ente accionante que los dos únicos proponentes del proceso eran cónyuges, lo que viciaba la legalidad de dicho acto en cuanto resultaban incompatibles las postulaciones de la proponente a la que le fue adjudicado el contrato.

A partir del caso señalado, la alta corporación diferencia el uso de la acción de lesividad cuando se utiliza dentro de la acción de nulidad y la de nulidad y restablecimiento del derecho, concluyendo en el caso de autos que

[...] para la Sala resulta absolutamente claro que los propósitos de la acción promovida por el municipio de Pereira no son otros que los de la preservación del ordenamiento jurídico. Lo cual implica, por lo tanto, el desarrollo de una pretensión de carácter general dirigida a restablecer la juridicidad en interés de la comunidad y del Estado de derecho. Conforme con lo anterior, sobra reiterar entonces, que la Administración puede impugnar su propia decisión 
Rodolfo Torregrosa Jiménez, Nayibe Alexandra Villalba García Adecuación de la acción de lesividad a los medios de control contemplados en la Ley 1437 del 2011

en defensa de los intereses generales, para poner fin, mediante sentencia judicial, a una situación irregular originada con la vigencia de su propio acto, para asi hacer cesar los efectos vulneradores, en tanto este contraviene el orden jurídico superior y, algunas veces, para poner término a la situación que resultaría perjudicial y lesiva patrimonialmente con el acto administrativo. Tal y como sucede en el caso sub examine, en el que la inhabilidad de la proponente adjudicataria vicia el contenido del Acto administrativo por medio del cual se le adjudica el Proceso de Selección Abreviada No. 50 de 2008, puesto que, al ser la cónyuge del otro único proponente, no podía participar en dicho proceso de selección objetiva, de acuerdo a los principios generales de la actividad administrativa. (C. E., 9 de julio del 2014, p. 30)

Se concluye de esta manera que este tipo de pretensión de lesividad se enmarca en el propósito esencial del medio de control de nulidad, a fin de dejar sin efecto el acto adjudicatario, con el que se afecta el principio de legalidad que debe en todo momento proteger la administración. No obstante, este planteamiento contradice lo relacionado en la doctrina antes citada, pues, pese a advertirse un restablecimiento automático del derecho en favor de la entidad demandante, al "hacer cesar los efectos vulneradores" con la declaratoria de nulidad del acto adjudicatario del contrato, la decisión se ciñe a articular la pretensión de lesividad del municipio en la acción de simple nulidad ${ }^{1}$, bajo el argumento de que esta es

[...] una acción de naturaleza objetiva, pública, popular, intemporal, general e indesistible a través de la cual solicita directamente ante la jurisdicción de lo contencioso administrativo, que un acto administrativo expedido por el mismo municipio, incurso en causal de nulidad, pierda su fuerza ejecutoria por declaración judicial en beneficio del ordenamiento jurídico y legalidad; luego por la calidad del sujeto y el tipo de pretensión invocada, resulta evidente que está actuando con propósitos claramente diferentes a los del mero restablecimiento de derechos subjetivos y siendo de mayor envergadura y amplitud, como lo son la protección de los intereses generales, que como ya se dijo, no están ni sustancial ni adjetivamente limitados en la redacción del

1 Así se llamaba este medio de control en el derogado Código Contencioso Administrativo, en vigencia del cual se formuló la demanda del caso en cita. 
parágrafo 1 del artículo 77 de la Ley 80 de 1993. (C. E., 9 de julio del 2014, págs. 29-30)

Son razones suficientes que, al contrario del pronóstico que hubiese anticipado la revisión hasta aquí expuesta, le permitieron al fallador de segunda instancia negar la prosperidad de la excepción de ineptitud de la demanda por indebida escogencia de la acción, en tanto el municipio tramitó su causa desde la acción de nulidad, en modalidad lesividad.

Otro ejemplo de la pluralidad de posturas interpretativas de la acción de lesividad ocurre en un escenario un poco más imprevisto, en lo que se logró recopilar hasta el momento de esta revisión, pues se encontró que judicialmente se reconoció la viabilidad de dar trámite a una pretensión de lesividad, a través de la nulidad electoral. Esto se observa en la decisión del Consejo de Estado, Sección Quinta (16 de octubre del 2014), en la resolución de un recurso de súplica contra el auto que decretó la nulidad de lo actuado en el proceso, por indebida elección del medio de control para demandar en lesividad un acto en el que se nombró al demandado como director del Hospital San Vicente de Arauca E. S. E.

En aquella oportunidad, el problema jurídico propuesto por la sala de decisión fue determinar

[...] ¿cuál es el medio de control adecuado para controvertir la legalidad del acto de nombramiento acusado, a fin de determinar si es el de nulidad y restablecimiento del derecho como lo consideró el magistrado ponente, el de nulidad (simple), como lo había indicado el demandante, o el de nulidad electoral, como había sido manifestado por el demandado y lo consideró la Sección Primera de esta corporación, al remitir el asunto por distribución interna de competencias a la Sección Quinta? (C.E., 16 de octubre del 2014, p. 10)

Para pronunciarse al respecto, el Consejo de Estado recuerda que el artículo 171 del CPACA, en sentido similar al artículo 90 del Código General del Proceso, habilita al operador judicial para adecuar la demanda y darle el trámite que corresponda, aun cuando la parte demandante hubiese errado en la elección del medio de control. De este modo, en virtud del principio iura novit curia, el saneamiento de la adecuación del medio de con- 
Rodolfo Torregrosa Jiménez, Nayibe Alexandra Villalba García

trol, cuando se adelante en lesividad, sucederá incluso en el curso del proceso mediante decisión del juzgado o corporación de conocimiento. Se fija entonces así, como hasta aquí se ha dicho, un alto grado de discrecionalidad y confrontación jurídica respecto de la aplicación del accionar en lesividad, ya que, como se indica en la cita anterior, puede enmarcarse su aplicación incluso en tres medios de control a la vez, en este caso: la nulidad, la nulidad y restablecimiento del derecho y la nulidad electoral.

En la búsqueda de dilucidar el problema jurídico planteado, la alta corte reitera la esencia de los tres medios de control señalados, indicando que el de nulidad "es proteger el orden jurídico objetivo, así que la decisión judicial recae exclusivamente en pronunciarse sobre la permanencia o retiro del acto, general o particular, del ordenamiento del derecho, sin que se permita adicionar otra declaración [...]" (C.E., 16 de octubre del 2014, p. 12). Por su parte, el de nulidad y restablecimiento del derecho "está determinado porque ese restablecimiento es pretensión consecuencial a la declaratoria de nulidad del acto administrativo" (p. 12), pues, "en el trasfondo implica una necesidad o utilidad de quien demanda de restablecer el derecho que considera vulnerado por el acto que ha sido o se declarará nulo, es decir, que lleva ínsito un interés particular y concreto” (p. 12).

Finalmente, argumenta el Tribunal Contencioso Administrativo, en la pluricitada providencia, que el de nulidad electoral, previsto en el artículo 139 del CPACA, persigue la defensa del orden político y democrático interno, de modo que, por su especialidad, es autónomo respecto de los dos anteriores, pues "su fin último es depurar las elecciones o nombramientos de quienes dirigen los destinos públicos" (C. E., 16 de octubre del 2014, p. 13), ya que en este "se debe examinar la legalidad de los actos de nombramiento cuando no se persiga restablecimiento de derecho alguno por parte de quien se considere titular de derecho subjetivo" (p. 11).

En el caso concreto de la acción de lesividad, el Consejo de Estado, al contrario de lo referido en la decisión precitada, descarta el medio de control de nulidad al encontrarse en presencia de un acto de nombramiento en un cargo público, decisión que lo configura como un típico acto particular y concreto. Y se aclara que las causales de nulidad del artículo 137, en todo caso, quedan subsumidas dentro de la nulidad electoral; por lo tanto, plantea que el acto acusado podría atacarse por los medios de nulidad y restablecimiento del derecho y de nulidad electoral, al asegurar entonces que 
[...] cuando se está frente al evento en el que convergen la posibilidad de postulación bajo la demanda contra el acto propio en dos modalidades de medio de control — restablecimiento del derecho y electoral — el operador jurídico debe acudir a la pretensión expresa o a deducir si existe restablecimiento automático, a partir de las menciones que en la causa petendi en forma vedada o tácita haga el actor o si de la sentencia a proferir se generará alguna clase de restablecimiento a favor del actor o a favor del tercero. (C. E., 16 de octubre del 2014, p. 23)

De ahí que, en su pronunciamiento, enfatice el Consejo de Estado en la aparente ausencia de restablecimiento de derecho subjetivo alguno en favor de la entidad accionante, de acuerdo con las pretensiones de la demanda y descartando escenarios automáticos, como el de la extinción de la vinculación laboral, que implica en sí el cese de la obligación laboral que recaía sobre la entidad desde la designación del demandado en el cargo. De modo que, fijando una postura que encierra la especialidad como criterio de adecuación de la pretensión, opta por la nulidad electoral y descarta contundentemente los medios de control que, a lo largo de este artículo, se han postulado como vías de acondicionamiento procesal para la pretensión de lesividad.

Con todo lo expuesto hasta aquí, se ha constatado una controversia aún vigente relacionada con la demanda de justicia que se promueve por parte de una entidad contra el acto propio, pues su tímida consagración en los instrumentos procesales ha provocado la disparidad de criterios relacionados en este texto, frente a las vías para tramitar las pretensiones de lesividad; por consiguiente, encontramos también al respecto reflexiones académicas en las que, incluso, se concluye frente a la acción de lesividad que "resulta relevante y necesario que se incorpore sustancialmente en la ley contencioso administrativa como una acción independiente a los mecanismos ya establecidos en la Ley 1437 de 2011 ” (Salguedo Pinilla y Silva Obando, 2015, p. 22).

Por esa razón, en el contexto colombiano, para solventar este obstáculo de ejercicio procesal, sería útil retomar los fundamentos de la lesividad, para contrarrestar de esa manera los efectos del vacío regulatorio de esta modalidad de pretensión, brindar una mejor comprensión del instrumento y así concretar adecuadamente su uso por parte de la administración. 
Rodolfo Torregrosa Jiménez, Nayibe Alexandra Villalba García

Recordemos, entonces que, en el origen de la institución, surgida en el derecho español, la administración se percataba de "la presunción de minoridad de la hacienda frente a la acción rescisoria por lesión de la hacienda y no como una acción de nulidad por ilegalidad, sino como el antiguo beneficio de la causa de rescisión por causa de lesión" (Ortega Ruiz, 2018, p. 56).

De modo esclarecedor, García de Enterría Martínez-Carande (1954, p. 118) comenta que, en su versión primigenia,

[...] el concepto de lesión, como el más vulgar de "perjuicio", tiene un perfil exacto en el derecho y se refiere concretamente, no a un supuesto de invalidez objetiva de un acto por infracción formal de las normas, sino, por el contrario, a un acto perfectamente válido, pero que, sin embargo, implica la consecuencia de un perjuicio económico para una de las partes. [...] Así resulta claramente que cuando se impone a la administración la carga de la acción contenciosa no se está contemplando el caso ordinario de la nulidad o anulabilidad de los actos administrativos, sino específicamente el de declaraciones administrativas de liquidación de créditos que, siendo perfectamente válidas, han producido, sin embargo, una lesión económica en contra de la hacienda por motivos que son típicos de la lesión, error — de hecho, o incluso de derecho- o engaño.

Estas afirmaciones llaman la atención en medio de lo que hasta aquí se ha dicho, pues el criterio esencial del proceder administrativo respondía, principalmente, a la producción de un perjuicio a la autoridad pública, concretamente, en temas relacionados con los tributos. Esto, en realidad, configuraba el sustento del llamado de lesividad y precisamente daba paso a la reparación de la lesión que le hubiese sido causada con su propia decisión al Estado.

Sin embargo, este último elemento es el que capta la atención de Fajardo (2015), pues su aporte se centra en el daño o detrimento que hubiese tenido que ocasionarse al ente accionante para que fuera próspera la solicitud lesiva de nulidad. Bajo este supuesto, Fajardo continúa haciendo seguimiento al uso de la figura en el caso colombiano, y verifica diferentes pronunciamientos del Consejo de Estado en los que se evidencia que hay 
decisiones en las que se accede a la solicitud de nulidad cuando se demanda en lesividad, sin que se haga una verificación de lesividad y bastando apenas con el análisis de ilegalidad.

Frente a este elemento concreto, relacionado con el perjuicio o afectación del Estado y que pueda implicar una reparación en sentido económico a favor de la administración, Parra (2013) define el principio de lesividad respecto al contexto tributario, a partir de la concepción de patrimonio público y poniendo también de presente, como viene dicho, que el origen del denominado juicio de lesividad evoca las lesiones tributarias a la administración pública.

En esta medida, Parra indica que "la infracción tributaria se define como la violación del ordenamiento jurídico por una persona determinada o indeterminada, mediante un acto u omisión, tipicidad, la cual puede o no poner en riesgo o lesionar el bien jurídico tutelado, antijuridicidad" (2013, p. 60).

De manera que es bajo la anterior proposición como se concluye que el ejercicio coercitivo del Estado, desde la óptica fiscal, puede concretarse a través de procesos sancionatorios, los que eventualmente pueden derivar en acciones de lesividad con respecto a los particulares y que han sido beneficiados con actos administrativos que lesionan el patrimonio público, guardando de esta forma armonía con el planteamiento que inspiró la acción de lesividad en España.

No obstante, la adecuación forjada por este autor respecto de la lesividad, en el escenario específico de la hacienda pública, es contrastada por Ortega, quien, con respecto a este asunto, aclara que "hoy, esta institución se transformó sustancialmente pasando a convertirse en un mecanismo de control de la legalidad” (2018, p. 56).

Esta posibilidad fue fortaleciéndose en la misma evolución del recurso de lesividad en diferentes contextos; por supuesto, en el escenario español ha inspirado su consagración y su práctica en la legislación colombiana, ya que, con respecto al juicio de lesividad, aconteció que

[...] la Ley Camacho hace algo totalmente distinto: trasmuta la naturaleza del recurso, reduciéndolo únicamente a ese supuesto de la nulidad y negando su 
Rodolfo Torregrosa Jiménez, Nayibe Alexandra Villalba García Adecuación de la acción de lesividad a los medios de control contemplados en la Ley 1437 del 2011

aplicación a las pretensiones restitutorias por lesión en cuanto que requieren en todos los casos "las mismas condiciones" de ilegalidad en el acto que legitiman los recursos contenciosos de los administrados. Con ello se confirma una curva evolutiva completa: el recurso de lesividad comienza siendo un recurso por lesión, se extiende más adelante a pretensiones de nulidad y concluye restringiéndose solo a la nulidad.

$[\ldots]$

El recurso de lesividad queda así consagrado en la generalidad de nuestro Derecho administrativo como un recurso de legalidad, cuyo efecto es, por consiguiente, anulatorio y no rescisorio. (García de Enterría MartínezCarande, 1954, pp. 139-140)

\section{Conclusiones}

El origen del recurso de lesividad contempló como característica fundamental la reparación de perjuicios acaecidos frente al patrimonio público, perfilándose así como un mecanismo que posibilitaba la recisión de las afectaciones sufridas por la administración con sus propias decisiones. No obstante, este precepto admitió una transformación de su función esencial dirigida a posibilitar el control judicial de las decisiones que fueran asumidas por la administración, dando paso a un escenario judicial de revisión de legalidad en el que, en salvaguarda del orden jurídico, se permite, en la actualidad, acusar actos administrativos para enervar pretensiones de mera nulidad.

La construcción conceptual de la denominada acción de lesividad resulta ser una figura procesal que permanece en constante evaluación y análisis doctrinario, especialmente porque su pretensión comprende una posibilidad valiosa para el Estado. Se tiende así a controlar las distintas decisiones que se toman desde el ejercicio de la función pública, en un entorno en el que fenómenos como la corrupción, el fraude, el desconocimiento $\mathrm{y}$, en algunos casos, el descuido, permiten estructurar decisiones que resultan contrarias al ordenamiento jurídico y hasta lesionan el erario, en beneficio de particulares. 
La ausencia regulatoria en la codificación administrativa de medio de control o pautas procesales específicas, con respecto a la forma en que las entidades públicas deben proceder para controvertir la legalidad de actos administrativos emitidos por las mismas entidades, ha dificultado el uso de esta herramienta procesal, pues el limitado espectro conceptual en la materia ha impuesto una relativa inactividad en su uso por parte de las entidades públicas.

El vacío legal que se advirtió en el caso colombiano, frente a la denominada acción de lesividad, ha ocasionado choques interpretativos respecto de un elemento tan básico como el de la adecuación a un medio de control en particular, con relación a cada caso concreto. Como quedó visto, sobre un mismo asunto se podría proponer la formulación en lesividad desde diferentes medios de control, especialmente los de nulidad y nulidad y restablecimiento del derecho, pues, si bien frente a estos ya está claramente decantado su uso - incluso en provecho de teorías como la de móviles y finalidades—, su empleo pierde claridad cuando quien demanda es la entidad emisora del acto, en tanto se entiende que su actuar responde, en primera medida, a la salvaguarda de intereses mayores al mero restablecimiento del derecho. Como emisarias de la voluntad estatal, las autoridades deben procurar con sus decisiones una armonía con las normas superiores; no obstante, en segundo lugar se identificó que la invocación inicial de la revocatoria directa y, a renglón seguido, la demanda de lesividad pueden conllevar, por regla general, al restablecimiento del derecho en favor de la administración, principalmente evidenciado en la cesación de obligaciones que se encontraban a cargo de la entidad y a favor del particular accionado.

La controversia suscitada frente al mecanismo judicial adecuado, por vía del cual se pueden promover las pretensiones de lesividad teniendo a la emisora del acto como demandante, choca con la caducidad del medio de control, institución de trascendental relevancia en el derecho procesal administrativo, pues la observancia taxativa de este elemento habilita o impide el acceso a la acción judicial. En esta medida, resulta ser un aspecto sustancial al momento de determinar el procedimiento por medio del cual se llevará la pretensión de lesividad, por cuanto cada medio de control contempla un término de caducidad diferente $y$, como la lesividad, con la entrada en vigencia del CPACA dejó de tener un término específico para ser promovida judicialmente. Disparó así las divergencias interpretativas respecto de su uso, dado que la oportunidad para presentar la demanda contiene disposiciones de orden público que debe aplicar el operador jurídico 
Rodolfo Torregrosa Jiménez, Nayibe Alexandra Villalba García Adecuación de la acción de lesividad a los medios de control contemplados en la Ley 1437 del 2011

en forma objetiva y sin consideración de situaciones personales del interesado, en este caso, la entidad pública.

Así las cosas, resulta necesario que, como respuesta a la confrontación doctrinaria y judicial que se ha evidenciado en este escrito, se emita una regulación específica que incluya las variables procesales tendientes a garantizar la tutela judicial efectiva de la pretensión que la misma entidad demande ante la rama jurisdiccional del poder público, en salvaguarda del ordenamiento jurídico y con el fin de armonizar sus propias decisiones con la Constitución y la ley, por vía de la acción de lesividad. Sin embargo, mientras eso sucede, será necesario que se unifiquen algunos criterios de índole procesal para que, con mediana claridad, puedan adelantarse demandas en la modalidad lesividad por parte de la administración, en procura del interés público.

\section{REFERENCIAS}

Aldana, J. y Guarín, E. (2016). Los límites de la teoría del equilibrio como alternativa de solución a la cuestión de la prevalencia del poder del Alto Tribunal de lo Constitucional en Colombia. Via Inveniendi et Iudicandi, 11(1), 59-82. https://doi.org/https://doi. org/10.15332/s1909-0528.2016.0001.01

Díaz Roa, F., Hernández González, C. A. y Galvis Flóres, M. V. (n.d.). Análisis de la acción de lesividad del Estado en materia de pensiones indebidamente otorgadas a servidores públicos en Colombia (1991-2017).

Fajardo Velásquez, J. M. (2015). Acción de lesividad: actos administrativos ilegales de carácter particular y concreto que no son lesivos a la administración (Universidad Nacional de Colombia). Universidad Nacional de Colombia. Recuperado de http://www.bdigital.unal. edu.co/49843/1/79801268.2015.pdf

García de Enterría Martínez-Carande, E. (1954). La configuración del recurso de lesividad. Revista de Administración Pública, 15(109-154).

González Castillo, C., Martínez Medina, S. y Rodríguez Palacios, J. (2018). Consentimiento previo a la expedición del acto administrativo particular (Universidad Santo Tomás). Universidad Santo Tomás. Recuperado de http://hdl.handle.net/11634/13670 
Millán Durán, J., Blanco Alvarado, C. y Guecha Medina, C. N. (2017). Los procesos de selección de operadores privados del servicio público de televisión en torno a la libre concurrencia. En V. S. Moreno Díaz, Á. I. Góngora, R. Durán Vinazco, L. S. Molina Vargas, J. C. Arias Duque, M. Tirado Acero, ... J. A. Sandoval Mesa (Eds.), Justicia Constitucional (tomo II). Grupo Editorial Ibáñez-Universidad Santo Tomás. Recuperado de https://repository.usta.edu.co/bitstream/handle/11634/4249/Vilma S. Moreno Díaz 2017.pdf? sequence $=1$ \&isAllowed $=y$

Moreno Baquero, H., Romero Espinal, A. y Romero Ladino, H. (2015). Análisis críticoconceptual sobre la acción de lesividad como un instrumento para anular algunos actos administrativos, amparados en el artículo 137 del Código de procedimiento administrativo y de lo contencioso administrativo. Universidad Santo Tomás.

Ortega Ruiz, L. G. (2018). El acto administrativo en los procesos y procedimientos. Bogotá: Editorial Universidad Católica de Colombia. Recuperado de https://publicaciones.ucatolica.edu.co/pdf/el-acto-administrativo-en-los-procesos-y-procedimiento.pdf

Pacheco García, T. y Santos Zuñiga, J. (2014). La acción de lesividad como mecanismo para la declaratoria de nulidad de los actos administrativos (Trabajo de grado). Trabajo de grado. Recuperado de https://repository.unimilitar.edu.co/bitstream/handle/10654/13387/LA ACCIÓN DE LESIVIDAD COMO MECANISMO PARA LA DECLARATORIA DE NULIDAD DE LOS ACTOS ADMINISTRATIVOS.pdf?sequence=1\&isAllowed=y

Parra, F. (2013). Principio de lesividad en ámbito sancionatorio tributario colombiano. Principia Iuris, 2(20), 43-63. Recuperado de http://revistas.ustatunja.edu.co/index.php/ piuris/article/view/800/779

Pereira Blanco, M. (2013). Principio de confianza legítima y acción de lesividad: elementos para una discusión. Revista Jurídica Mario Alario D'Filippo, 5, 43-63. https://doi.org/ https://www.researchgate.net/deref/http\%3A\%2F\%2Fdx.doi.org\%2F $10.32997 \%$ 2F2256-2796-vol.5-num.10-2013-2009

Puentes Araujo, M. (2019). La acción de lesividad frente al acto administrativo de adjudicación del contrato estatal. Via Iuris, 27(45-76). https://doi.org/https://doi.org/10.37511/ viaiuris.n27a2 
Salguedo Pinilla, A. y Silva Obando, M. (2015). La acción de lesividad como mecanismo de control en Colombia (Universidad La Gran Colombia). Universidad La Gran Colombia. Recuperado de http://repository.ugc.edu.co/handle/11396/3717

Senado de la República. (2009). Exposición de motivos Ley 1437 del 2011. Proyecto de Ley núm. 198 del 2009. Por la cual se expide el Código de Procedimiento Administrativo y de lo Contencioso Administrativo. Gaceta del Congreso núm. 1173. 